\title{
Vomeronasal and Olfactory Pathways to the Amygdala Controlling Male Hamster Sexual Behavior: Autoradiographic and Behavioral Analyses
}

\author{
MICHAEL N. LEHMAN and SARAH S. WINANS \\ Departments of Anatomy and Cell Biology, University of Michigan, Ann Arbor, MI 48109 (U.S.A.)
}

(Accepted October 15th, 1981)

Key words: amygdala — vomeronasal system - olfactory system - hamster — male sexual behavior — autoradiography

\begin{abstract}
Previous studies suggest that the rostral corticomedial amygdala (CMA), particularly the medial nucleus, is an important site where vomeronasal and olfactory stimuli critical to male hamster copulatory behavior are processed. To test the possibility that mating deficits seen after lesions of the rostrally-placed medial nucleus may be due to the interruption of chemosensory afferents to more caudal areas, we injected tritiated amino acids into the accessory and main olfactory bulbs of male hamsters in which we had first produced bilateral electrolytic lesions or sham lesions in either the rostral CMA or basolateral amygdala, and then observed mating behavior. Autoradiographic analysis of 'vomeronasal' projections from the accessory olfactory bulb and 'olfactory' projections from the main bulb, revealed that rostral CMA lesions which damaged the medial nucleus and extended to the ventral surface of the brain (ventral lesions) interrupted vomeronasal input to the more caudally-placed posteromedial cortical nucleus, but spared olfactory inputs to adjacent caudal areas of the amygdala and piriform lobe. In contrast, lesions which damaged a major portion of the medial nucleus but left its ventral surface intact (dorsal lesions) spared both vomeronasal and olfactory inputs to more caudal areas. Animals with both dorsal and ventral lesions failed to mate postoperatively, whereas animals bearing sham lesions of basolateral amygdaloid lesions, which, like dorsal lesions, spared caudally-directed chemosensory afferents, continued to mate normally. We conclude that mating deficits seen after rostral CMA lesions are due primarily to destruction of the medial nucleus.
\end{abstract}

\section{INTRODUCTION}

Much recent attention has focused on the vomeronasal system as a sensory channel through which pheromonal influences on species-specific behavior and neuroendocrine events are expressed (for reviews see refs. 22, 59). Second-order central projections of the vomeronasal sensory system from the accessory olfactory bulb (AOB) terminate in a more restricted number of targets than the widespread secondary olfactory projections leaving the main olfactory bulb (MOB) $)^{4,9,52,55}$. A major central target of the vomeronasal system in mammals is the corticomedial amygdala (CMA) where second-order neurons of both the MOB and $A O B$ project to adjacent nuclei ${ }^{9,52}$. We recently presented evidence indicating that the rostral CMA, particularly the androgen-binding 51,54 medial nucleus which receives vomeronasal input directly from the $A O B$, is a site where chemosensory stimuli critical to male hamster copulatory behavior are processed ${ }^{36}$. Bilater- al lesions of the rostral CMA which damaged a major portion of the medial nucleus completely eliminated copulatory behavior in male hamsters and significantly decreased the amount of time these males spent investigating the female's anogenital region during mating tests. In contrast, male hamsters with bilateral lesions of the caudal CMA continued to display copulatory behavior during postoperative tests, although they did show changes in the temporal pattern of their copulatory sequence. Animals with bilateral lesions of the basolateral amygdala (BLA) and sham lesioned controls displayed no temporal changes in copulatory behavior and continued to mate normally in postoperative tests.

The significant correlation between damage to the medial amygdaloid nucleus and extensive deficits in copulatory and investigatory behavior complements anatomical evidence indicating that the medial nucleus is a major source of efferents to the bed nucleus of the stria terminalis and the medial preoptic- 
anterior hypothalamic junctions ${ }^{28,30}$, two additional androgen-binding brain areas ${ }^{51,54}$ implicated in the control of male copulatory behavior ${ }^{33,39}$. However, it is also possible that lesions of the rostral CMA involving the medial nucleus interrupted vomeronasal and olfactory afferents to more caudally placed nuclei in the CMA and that, even though caudal CMA lesions alone did not eliminate the behavior, disruption of chemosensory input to the entire amygdala might be responsible for the observed behavioral deficits. Evidence from previous anatomical studies ${ }^{9,52}$ indicated that vomeronasal fibers from the AOB travel along the ventromedial surface of the CMA while olfactory fibers travel along the ventrolateral surface. In order to confirm the trajectories of MOB and AOB efferents to the caudal amygdala and test the possibility that our lesions disrupted these pathways, we injected $\left[{ }^{3} \mathrm{H}\right]$ proline or -leucine into the $\mathrm{MOB}$ and $\mathrm{AOB}$ of male hamsters in which we had previously placed bilateral electrolytic lesions in the rostral CMA and whose mating behavior we had subsequently observed. As controls, we injected tritiated amino acids into the $M O B$ and $A O B$ of male hamsters with bilateral lesions in the BLA, or sham lesions, whose postoperative mating behavior we had also observed.

Through light microscopic autoradiographic analysis of these brains we traced the course of $A O B$ and $\mathrm{MOB}$ efferents toward and through the amygdala, and thereby determined which rostral CMA lesions interrupted vomeronasal and/or olfactory afferents to areas caudal to the site of the lesion. We then compared the postoperative mating behavior records of individual animals with the size and extent of their amygdaloid lesions, and with histological observations on whether vomeronasal or olfactory input to caudal amygdaloid areas remained intact. The results of this study are presented in two sections: (a) autoradiographic observations on the trajectory of vomeronasal and olfactory afferents to the amygdala in normal control animals, and observations on whether rostral CMA lesions or BLA lesions interrupted caudally directed chemosensory afferents; and (b) behavioral observations of the postoperative mating of male hamsters with rostral CMA, BLA, or sham lesions, and a comparison of their individual behavioral records with histological observations on the extent to which their lesions interrupted chemosensory input to the caudal amygdala.

\section{MATERIALS AND METHODS}

\section{Animals}

Adult male hamsters weighing approximately 120 $\mathrm{g}$ were obtained from Engle Laboratory Animals (Farmersburg, IN). Animals were housed individually with food and water available ad libitum, and exposed to a $14 \mathrm{~h}$ light: $10 \mathrm{~h}$ dark illumination cycle.

\section{Mating behavior tests}

Tests were conducted 2-3 $\mathrm{h}$ into the dark portion of the animals' illumination cycle. Mating behavior was observed after introducing a behaviorally receptive female into a clean plexiglass cage containing the experimental male hamster. Adult ovariectomized female hamsters were made sexually receptive by sequential subcutaneous injections of estradiol benzoate $(10 \mu \mathrm{g})$ and progesterone $(200 \mu \mathrm{g})$ dissolved in $0.1 \mathrm{ml}$ sesame oil and administered 42 and $6 \mathrm{~h}$, respectively, before behavior testing. The female's receptivity was confirmed prior to mating tests by exposure to a stud male.

The latency and frequency of all mounts, intromissions, and ejaculations displayed by the male hamster during the mating test were recorded, as well as the duration of the male's sniffing and licking investigation of the female's head, flank, and anogenital region. Latency data were recorded using the timer functions of a Hewlett-Packard HP-55 calculator; frequency data were recorded with a series of mounted hand-held counters; duration data were measured with a series of contact-activated electromechanical timers and counters. Observations continued for $10 \mathrm{~min}$, or until the male had achieved 2 ejaculations. Experimental males were screened for normal mating behavior and tested twice over a period of 1 week prior to surgery, and then tested 3 times over a period of 3 weeks following surgery.

\section{Brain lesions}

Electrolytic lesions were produced in anesthesized hamsters (Nembutal, $75 \mathrm{mg} / \mathrm{kg}$ ) by stereotaxically lowering an insect pin electrode insulated except for $0.5 \mathrm{~mm}$ at the tip (tip diameter $0.37 \mathrm{~mm}$ ) and delivering an anodal DC current of $1.5 \mathrm{~mA}$ for 15 
s. Stereotaxic coordinates for rostral corticomedial amygdala lesions (with bregma and lambda in a horizontal plane) were AP $\longrightarrow 0.3$, ML 2.9 from bregma, and DV -7.6 to -7.8 from dura; coordinates for basolateral amygdala lesions were AP -0.7 , ML 3.9 from bregma, and DV -7.4 from dura. Sham operations were performed by lowering the electrode to $1 \mathrm{~mm}$ above experimental coordinates without the delivery of current.

Autoradiographic procedures. Four to six weeks following surgery and postoperative testing, 10-20 $\mu \mathrm{Ci}\left[{ }^{3} \mathrm{H}\right.$ ]proline or -leucine (spec. act. $40-60 \mathrm{Ci} /$ mmol, New England Nuclear) in 0.10-0.20 $\mu$ l physiological saline was injected bilaterally into the main and accessory olfactory bulbs, using a $5 \mu \mathrm{l}$ Hamilton syringe with a $26 \mathrm{~S}$-gauge needle. At the end of a 48-h survival period, the animals were perfused with $0.9 \%$ saline followed by $10 \%$ phosphate-buffered formalin. The brains were removed, embedded in egg-yolk gelatin, and cut on a freezing microtome at $30 \mu \mathrm{m}$. Coronal sections at $120 \mu \mathrm{m}$ intervals were mounted, coated with Kodak NTB-2 emulsion, and exposed for 2-3 weeks in a cold room $\left(2{ }^{\circ} \mathrm{C}\right)$. The slides were developed with Kodak D-19 developer and counterstained with cresyl violet.

\section{RESULTS}

\section{Autoradiographic observations}

\section{Normal controls}

Three animals which had been given sham amygdala lesions and tested for mating behavior postoperatively, received bilateral injections of tritiated amino acids aimed primarily at the accessory olfactory bulb (AOB). In these control animals and in the lesioned animals of this experiment, large injections directed toward the AOB often spread into the adjacent main olfactory bulb (MOB). In addition, some misdirected injections were limited entirely to the dorsal margin of the MOB immediately rostral to the AOB. The boundaries of an injection site were defined as the limits of the region containing cell bodies which appeared black due to heavy incorporation of tritiated amino acids? Comparisons between patterns of autoradiographic silver grains seen in animals with injections confined to either the $\mathrm{AOB}$ or $\mathrm{MOB}$, or involving both, enabled us to distinguish the trajectory of vomeronasal projections leaving the AOB from those of olfactory fibers leaving the MOB.

Although it was impossible to distinguish fibers from terminals in a given autoradiographic section where silver grains appeared over the plexiform layer, data from other material in our laboratory, using silver impregnation methods allowed us to distinguish degenerating fibers from terminals, in a section at the same coronal level. In this study, 'terminals', 'terminal fields', and 'silver grains representative of a terminal field', all refer to locations where we observed an accumulation of autoradiographic silver grains over a previously identified terminal field.

Fig. 1A illustrates the distribution of efferent projections from the AOB to the amygdala in hamster 13 , who served as a sham operate during the behavioral phase of this experiment. The injection of tritiated leucine in this animal on the right side of the brain was confined entirely to the AOB (Fig. 1A i). This animal's histological record summarizes the normal secondary projections of the vomeronasal sensory system through rostrocaudal levels of the amygdala (Fig. $1 \mathrm{~A}_{\mathrm{i1}, \mathrm{i1}, \mathrm{iv}}$ ). A heavy concentration of autoradiographic silver grains was seen over fibers of the accessory olfactory tract as they left the AOB laterally and travelled caudally through the olfactory peduncle along the inner surface of the lateral olfactory tract. Posteriorly, at the level of the nucleus of the lateral olfactory tract, these fibers migrated to a dorsomedial position along the edge of the lateral olfactory tract, and eventually gave rise to an accumulation of silver grains representative of a terminal field capping the ventral aspect of the nucleus of the accessory olfactory tract (NAOT) (Fig. $1 \mathrm{~A}_{\mathrm{ii}}$ ). These silver grains continued to occupy a narrow crescent-shaped lamina on the ventral border of the NAOT along the entire rostral-caudal extent of this nucleus, even as the anterior portion of the medial nucleus (M) of the amygdala was becoming evident. As the NAOT disappeared and $M$ assumed its position along the lateral edge of the optic tract, a heavy density of silver grains was observed over the superficial plexiform layer (sublamina 1a) of $M$, along its ventral and medial borders (Fig. $1 \mathrm{~A}_{111}$ ). Further caudally in the amygdala, this terminal field spread from the ventral 


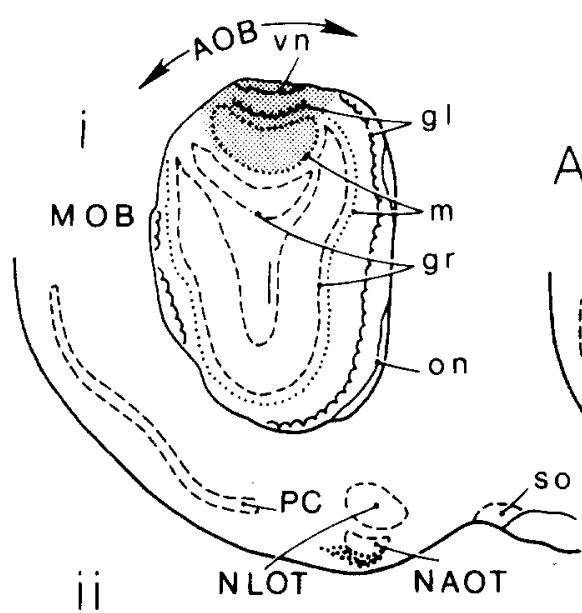

A. NORMAL CONTROL
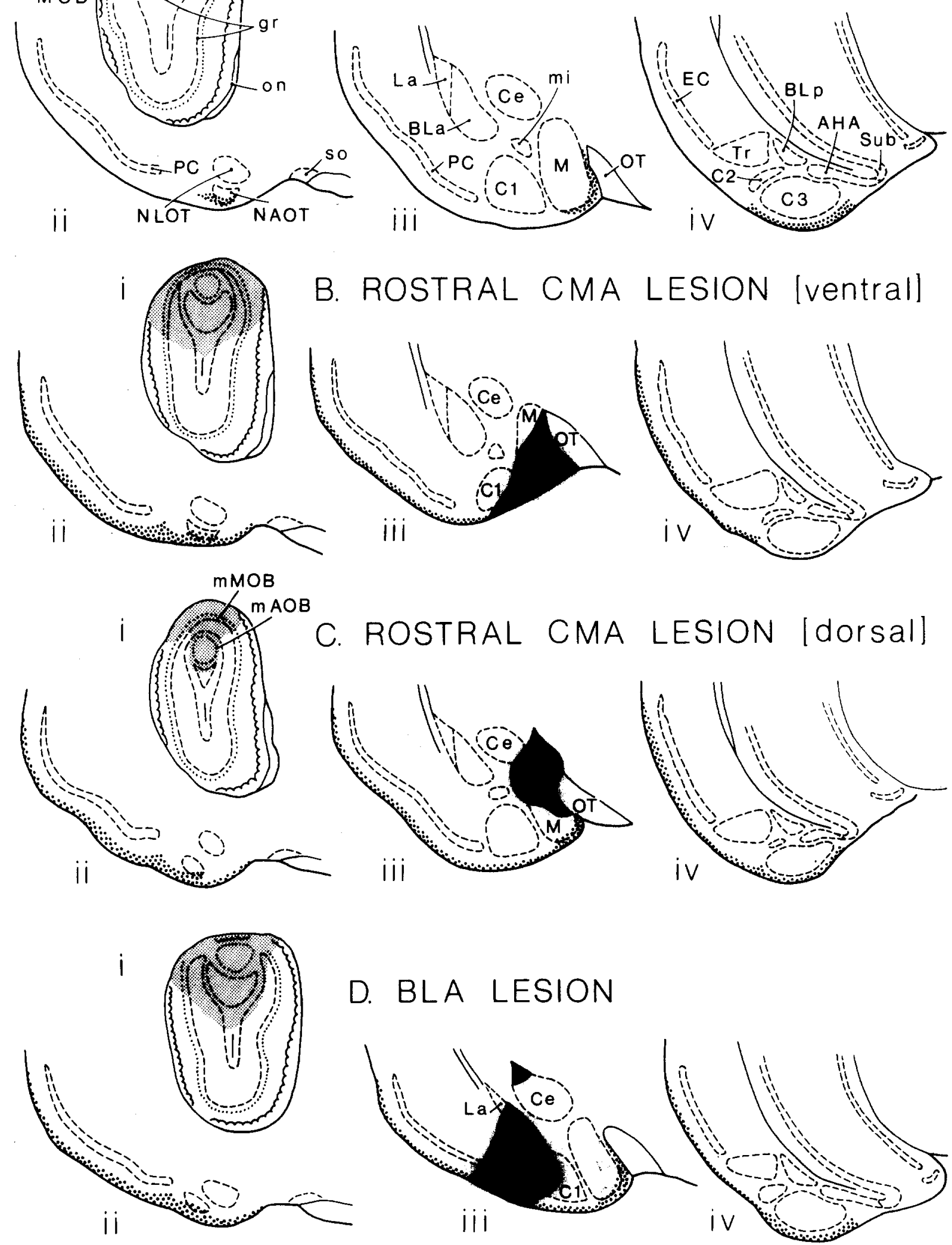

D. BLA LESION

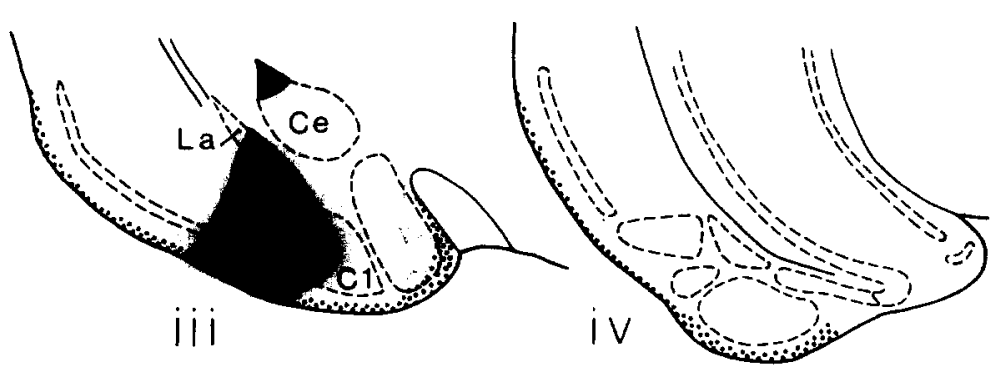


surface of $M$ to cover the superficial plexiform layer of the posteromedial cortical nucleus (C3). This terminal field continued caudally along the entire extent of $\mathrm{C} 3$, as this nucleus assumed a ventrolateral position relative to the expanding hippocampal formation (Fig. 1 $\mathrm{A}_{\mathbf{i v}}$; Fig. 2A).

An analysis of olfactory projections in animals with injections either confined to or primarily involving the MOB revealed a high concentration of silver grains over the entire extent of the lateral olfactory tract. In these animals, autoradiographic silver grains were found in the rostral forebrain in a continuous and extensive area involving the superficial plexiform layers of all subdivisions of the anterior olfactory nucleus, the olfactory tubercle, the ventral portion of the hippocampal rudiment (tenia tecta), and the rostral piriform cortex. More caudally, this continuous sheet of terminals and fibers extended to include the superficial plexiform layers of the anterior cortical $(\mathrm{C} 1)$ and posterolateral cortical (C2) nuclei of the amygdala, the remaining caudal extent of the piriform cortex, the lateral entorhinal cortex, and the adjacent transition area (area TR of Haug ${ }^{20}$ ). Although these latter olfactory projections are not illustrated as they were observed in the normal animal, they are represented in Fig. 1B-D, cases in which injections in lesioned animals involved both $\mathrm{MOB}$ and $\mathrm{AOB}$.

In addition to the aforementioned olfactory terminal fields, it should be noted that in several animals with injections confined to $\mathrm{MOB}$, we observed a thin accumulation of silver grains in the superficial plexiform layer ventral to a diffuse collection of cells in the medial portion of the anterior amygdaloid area, and slightly more caudally, ventromedial to cells in the most anterior part of $\mathrm{M}$. In animals with injections involving both MOB and $\mathrm{AOB}$, this olfactory terminal field was replaced at slightly more caudal levels by the crescent-shaped vomeronasal projection to NAOT, as the position of this nucleus shifts medially and assumes a position immediately ventral to $M$. AOB projections eventually gave rise to a more extensive vomeronasal terminal field, which at the greatest cross-sectional area of $M$ covered its entire ventral surface and its medial surface adjacent to the optic tract.

\section{Rostral CMA lesions}

Twelve male hamsters with bilateral rostral CMA lesions received bilateral injections of tritiated amino acids into MOB and/or AOB. These animals were divided into two groups according to the placement of their lesions: (a) 9 hamsters with bilateral lesions in the rostral CMA, in which the lesion damaged a major portion of $M$ and extended to the ventral surface of the brain (ventral lesion); and (b) 3 hamsters with bilateral lesions in the rostral CMA, in which the lesions damaged a major portion of $M$ but left its ventral surface intact (dorsal lesions). Fig. $1 \mathrm{~B}$ and $\mathrm{C}$ illustrates the distribution of efferent projections visualized after injections involving both $\mathrm{MOB}$ and $\mathrm{AOB}$ in hamsters 9 and 264 , who had previously received bilateral lesions damaging the ventral and dorsal portions of $\mathrm{M}$, respectively. The histological records of these 2 animals are representative of experimental groups a and $b$ above.

The injection of tritiated proline in hamster 9 was

Fig. 1. Tracings of autoradiographic brain sections from 4 representative hamsters with $\left[{ }^{3} \mathrm{H}\right]$ amino acid injections into the accessory olfactory bulb (AOB), or both the $\mathrm{AOB}$ and main olfactory bulb (MOB). These animals had previously received either (A) bilateral sham lesions, (B) bilateral rostral lesions of the corticomedial anygdala (CMA) that damaged the ventral portion of the medial nucleus (M), (C) bilateral rostral CMA lesions that damaged the dorsal portion of $M$ but spared its ventral surface, or (D) bilateral lesions of the basolateral amygdala (BLA). $\left[{ }^{3} \mathrm{H}\right]$ amino acid injection site, stippled area on coronal section through AOB and MOB (i); black dots, location of autoradiographic silver grains at rostral-caudal levels through the amygdala (ii-iv); black area, location and greatest extent of each amygdaloid lesion. Abbreviations: AHA, amygdalo-hippocampal area; AOB, accessory olfactory bulb; BLa, basolateral nucleus of the amygdala (anterior division); BLp, basolateral nucleus of the amygdala (posterior division); $\mathrm{C} 1$, anterior cortical nucleus of the amygdala; $\mathrm{C} 2$ posterolateral cortical nucleus of the amygdala; $\mathrm{C} 3$, posteromedial cortical nucleus of the amygdala; Ce, central nucleus of the amygdala; EC, lateral entorhinal cortex; gl, glomerular layer of the main and accessory olfactory bulbs; gr, internal granule cell layer of the main and accessory olfactory bulbs; La, lateral nucleus of the amygdala (anterior division); $\mathrm{M}$, medial nucleus of the amygdala; $\mathrm{m}$, mitral cell layer of the main and accessory olfactory bulbs; mi, intercalated masses of the amygdala; MOB, main olfactory bulb; NAOT, nucleus of the accessory olfactory tract; NLOT, nucleus of the lateral olfactory tract; on, olfactory nerve; OT, optic tract; PC, piriform cortex; so, supraoptic nucleus of the hypothalamus; Sub, subiculum; Tr, entorhinal transition area; vn, vomeronasal nerve. 

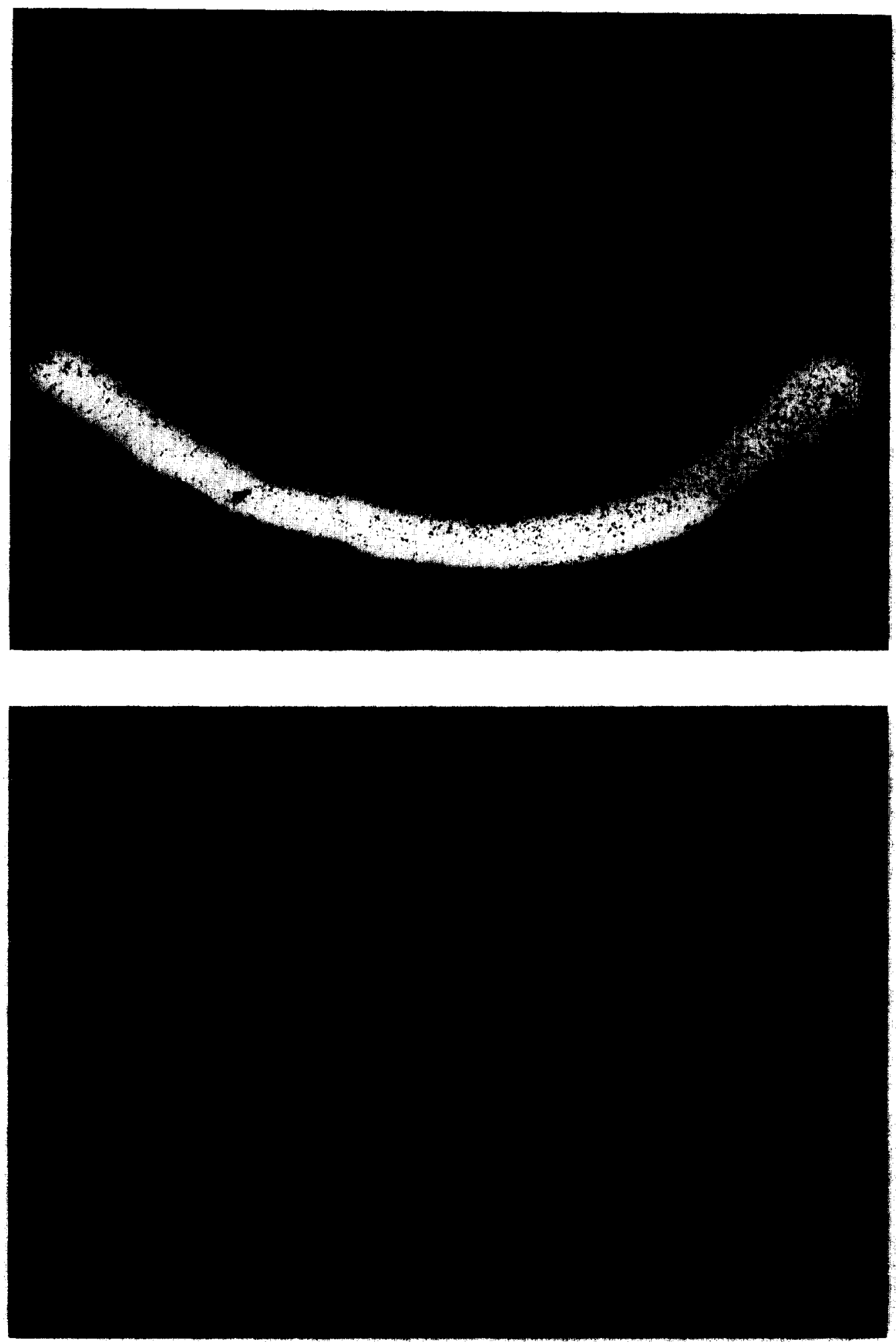

Fig. 2. A : dark-field photomicrograph of the posteromedial cortical nucleus $(\mathrm{C} 3)$ following a $\left[{ }^{3} \mathrm{H}\right]$ leucine injection into the $A O B$ in hamster 13, an animal which had previously received bilateral sham lesions (cf. Fig. $1 \mathrm{~A}_{\mathrm{Iv}}$ ). Dashed white lines, nuclear boundaries as defined on bright-field illumination of this cresyl-violet stained section. B: dark-field photomicrograph of the caudal amygdala following a $\left.{ }^{3} \mathrm{H}\right]$ proline injection into the $\mathrm{AOB}$ and $\mathrm{MOB}$ in hamster 9 , an animal which had previously received bilateral ventral CMA lesions (cf. Fig. $1 \mathrm{~B}_{\mathrm{iv}}$ ). Note silver grains in the superficial plexiform layers of $\mathrm{C} 2$ and TR and their absence in C3. Also note the shrinkage of the plexiform layer of $\mathrm{C} 3$ here compared to $\mathrm{A}$, resulting from destruction of afferents to $\mathrm{C} 3$ by the rostral CMA lesion. For abbreviations see Fig. 1 legend. 
aimed primarily at the $\mathrm{AOB}$, but spread into adjacent medial and lateral areas of MOB (Fig. $1 B_{i}$ ). At the caudal end of the MOB and AOB, autoradiographic silver grains were found concentrated over both olfactory fibers in the lateral olfactory tract and vomeronasal fibers in the accessory olfactory tract. Rostral to the site of the lesion, at the level of the nucleus of the lateral olfactory tract, accumulations of silver grains were seen in the superficial plexiform layer of the rostral piriform cortex, an olfactory projection area, and in the ventral portion of the NAOT, a vomeronasal projection area (Fig. $1 B_{i i}$ ). At the site of the lesion, which damaged the ventral part of $M$ and also a small ventromedial portion of $\mathrm{Cl}$, olfactory terminal fields in the remainder of $\mathrm{Cl}$ and the piriform cortex were intact, although the lesion had destroyed vomeronasal terminals along the ventral and medial surfaces of $M$ (Fig. $1_{B_{i i i}}$ ). Caudal to the lesion, olfactory terminal fields were observed in $\mathrm{C} 2$, the caudal piriform cortex, the lateral entorhinal cortex, and the entorhinal transition area, but the superficial plexiform layer of $\mathrm{C} 3$, where a vomeronasal terminal field is normally present, was conspicuously devoid of silver grains (Figs. $1 B_{i v} ; 2 B$ ). In addition to the absence of silver grains, the plexiform layer was reduced to approximately one-third its normal depth. This reduction in volume of the tissue was presumably due to shrinkage of the tissue following degeneration of the fibers and terminals of AOB neurons. This is observable by comparison of the width of the plexiform layer in Fig. 2A with that in Fig. 2B.

In summary, our autoradiographic observations indicated that rostral CMA lesions which damaged the ventral portion of $M$ and extended to the ventral surface of the brain, interrupted AOB fibers to C3, but left intact the caudally directed olfactory projections to $\mathrm{C} 2$, the piriform cortex, the lateral entorhinal cortex and the entorhinal transition area. These observations support previous findings ${ }^{9,52}$ that vomeronasal fibers from the AOB directed toward terminal fields in the amygdala travel along the ventromedial edge of the CMA, while olfactory fibers in the LOT destined to terminate in the amygdala retain their position along the ventrolateral surface of the brain.

The injection of tritiated leucine in hamster 264 included the dorsal margin of $\mathrm{MOB}$ as well as $\mathrm{AOB}$
(Fig. $1 C_{i}$ ). As in hamster 9, we found autoradiographic silver grains concentrated over sites of both olfactory and vomeronasal terminals rostral to the site of the lesion. At the level of the nucleus of the lateral olfactory tract, an olfactory terminal field in the rostral piriform cortex, and vomeronasal terminals adjacent to the NAOT were both evident (Fig. $\left.1 C_{i 1}\right)$. However, in contrast to hamster 9 , at the site of the lesion, which in this case damaged the dorsal portion of $\mathrm{M}$ and a ventromedial portion of the central nucleus, both olfactory terminals in $\mathrm{Cl}$ and the piriform cortex, and vomeronasal terminals along the ventral surface of $M$ were observed (Fig. $1 C_{i i 1}$. The lesion in this animal probably did damage the dorsal edge of that part of the vomeronasal terminal field which lies between $\mathbf{M}$ and the optic tract (see Fig. $1 \mathbf{A}_{\mathrm{iii}}$ ). However, when we examined sections caudal to the site of the lesion it was evident that vomeronasal terminals in $\mathrm{C} 3$ were present, as were olfactory terminals in $\mathrm{C} 2$, the caudal piriform cortex, the lateral entorhinal cortex, and the entorhinal transition area (Fig. $1 \mathrm{C}_{\mathrm{iv}}$ ). The presence of the vomeronasal terminal field in $\mathrm{C} 3$ caudal to this type of lesion is further illustrated by photomicrographs of this area in hamster 826 (Fig. 3A), another animal of this experimental group with a dorsal lesion of $\mathbf{M}$. These observations indicated that most, if not all of the fibers which give rise to terminals in $\mathrm{C} 3$, are probably travelling through the layer of terminals on the ventral surface of $M$. In summary then, it is clear that rostral CMA lesions which damaged the dorsal portion of $M$ but left the ventral surface of the brain intact, also left intact both vomeronasal and olfactory fibers to more caudal nuclei in the amygdala.

\section{BLA lesions}

Six animals with bilateral lesions placed in the basolateral amygdala (BLA) received bilateral injections of tritiated amino acids into MOB and/or AOB. Fig. 1D illustrates the distribution of efferent projections from the AOB and $\mathrm{MOB}$ in an animal representative of this experimental group, in which the amygdala lesion destroyed much of $\mathrm{C} 1$ and $\mathrm{C} 2$ as well as a major portion of the lateral (anterior and posterior divisions) and basolateral (anterior and posterior divisions) nuclei. The injection of tritiated leucine in hamster 16 included the AOB and ad- 

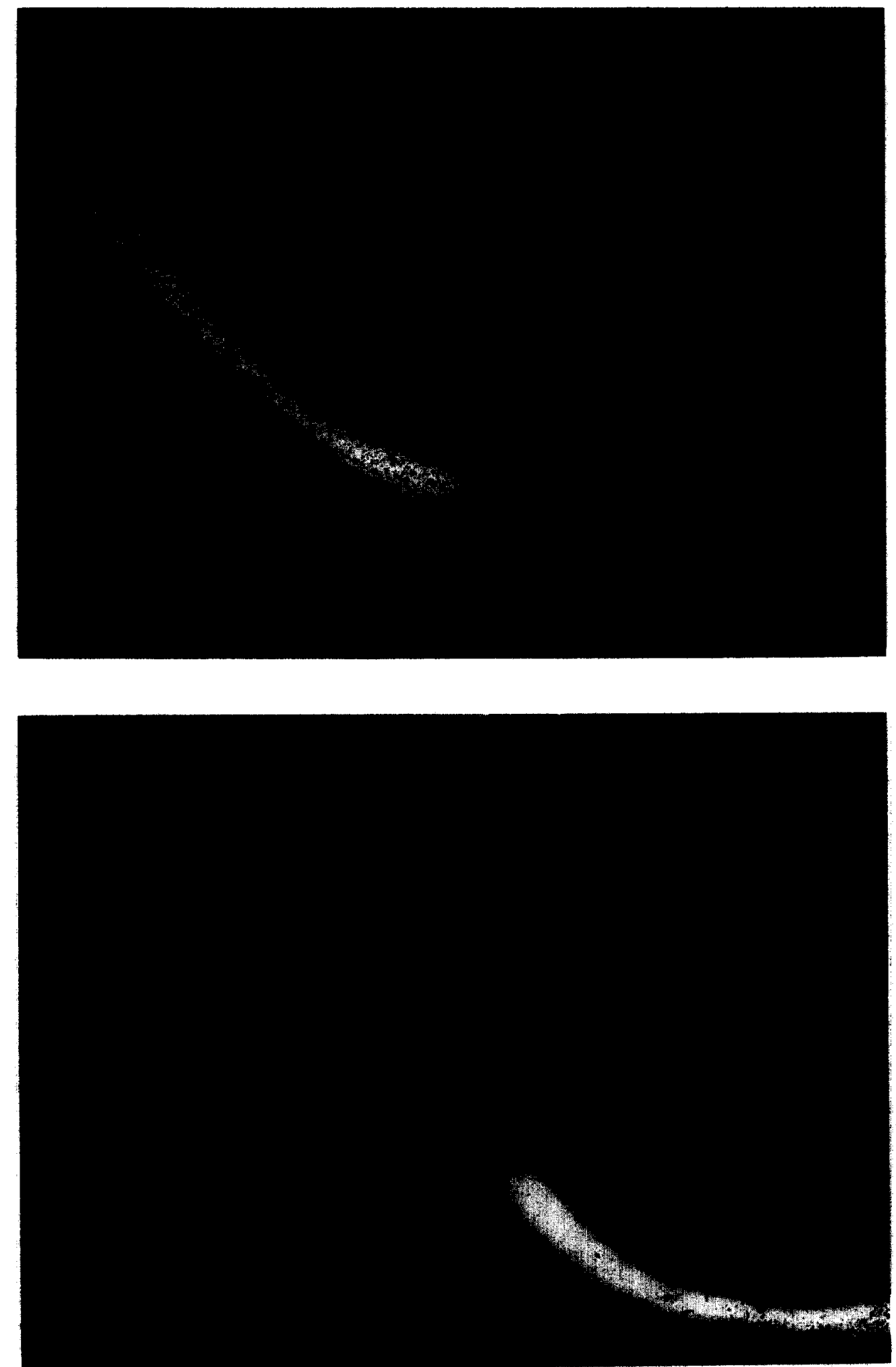

Fig. 3. A : dark-field photomicrograph of the left caudal amygdala following an injection of $\left[{ }^{3} \mathrm{H}\right]$ proline into the AOB in hamster 826, an animal which previously received bilateral dorsal CMA lesions (similar to $F i g .1 C_{i i j}$ ), but note that this section is from the contralateral amygdala). Note that silver grains in the superficial plexiform layer of $\mathrm{C} 3$ are comparable to those in normal control brains (cf. Fig. $2 \mathrm{~A}$ and $\mathrm{Fig}, 1 \mathrm{C}_{\mathrm{iv}}$ ). B: dark-field photomicrograph of the right caudal amygdala and adjacent entorhinal transition area (TR) following a $\left[{ }^{3} \mathrm{H}\right]$ leucine injection into the AOB and $\mathrm{MOB}$ in hamster 16 , an animal which previously received bilateral BLA lesions (cf. Fig. 1Div). Silver grains seen here in the superficial plexiform layers of C2 and TR are less dense than in normal animals but still present, while those in $\mathrm{C} 3$ are comparable to normal control brains (Fig. 2A). For abbreviations see Fig. 1 legend. 
jacent dorsal, medial, and lateral areas of MOB (Fig. $1 D_{i}$ ). As expected from evidence presented above describing the path of vomeronasal afferents to the amygdala, we found vomeronasal terminal fields comparable to thase in normal control brains throughout the rostral-caudal extent of the amygdala in animals with BLA lesions. Densely packed silver grains were present in the ventral portion of the NAOT (Fig. $1 D_{i i}$ ), and in the superficial plexiform layers of $M$ (Fig. $1 D_{i j i}$ ) and $C 3$ (Fig. $1 D_{i v}$ ). Although olfactory terminal fields were present rostral to the lesion, for example, in the rostral piriform cortex (Fig. 1D $\mathrm{D}_{\mathrm{ii}}$ ), the spread of the lesion in this animal to the ventral surface of $\mathrm{C} 1$, anterior $\mathrm{C} 2$, and the piriform cortex, destroyed olfactory terminal fields in that area but left some olfactory fibers intact at the medial edge of $\mathrm{Cl}$ (Fig. $1 \mathrm{D}_{\mathrm{iii}}$ ). Caudally, we found olfactory terminal fields in the superficial layers of $\mathrm{C} 2$ and the entorhinal transition area to be considerably less dense than in a normal animal but still present (Fig. 1D $\mathrm{D}_{\mathrm{iv}}$; Fig. 3B).

A lateral and caudal branching pattern of axons from the lateral olfactory tract has previously been described in studies of normal11,53 and regenerating $^{12}$ fibers innervating the piriform cortex. Since cut lateral olfactory tract fibers in adult hamsters show no evidence of sprouting or regeneration ${ }^{12}$, our observations suggest that at least some of those olfactory tract fibers which normally reach the superficial plexiform layers of $\mathrm{C} 2$ and the entorhinal transition area do so by way of axons which extend laterally and caudally, from those intact olfactory fibers observed at the medial edge of $\mathrm{Cl}$ (Fig. $1 \mathrm{D}_{\mathrm{iii}}$ ).

In summary, although lesions placed in the BLA often damaged the ventral surface of $\mathrm{C} 1, \mathrm{C} 2$, or the piriform cortex, these lesions did not eliminate olfactory input to more caudal areas in the amyg. dala or entorhinal cortex, nor did they interrupt vomeronasal input to the amygdala; accessory olfactory tract terminal fields were present throughout the rostral-caudal extent of $\mathrm{M}$ and $\mathrm{C} 3$.

\section{Behavioral observations}

As expected on the basis of previous findings in this laboratory, male hamsters with bilateral lesions placed in the rostral CMA displayed drastic deficits in copulatory and investigatory behavior during postoperative mating tests (Table I). Of 9 animals with bilateral rostral CMA lesions that damaged the ventral portion of $M$ and extended to the ventral surface of the brain, only one male (hamster 853) displayed any copulatory behavior during any of the 3 postoperative tests, and then only during the second test. Of 3 animals with bilateral rostral CMA lesions that damaged the dorsal portion of $M$ and spared the ventral surface of the brain, one male, hamster 826 , resumed mating during the second and

TABLE I

Mating behavior of male hamsters before and after amygdaloid lesions

ML, mean mount latency (s) \pm S.E.M.; I/E, mean number of intromissions to first ejaculation (s) \pm S.E.M.; EL, mean latency to first ejaculation (s) \pm S.E.M.

\begin{tabular}{|c|c|c|c|c|c|c|c|c|c|c|c|c|}
\hline \multirow[t]{3}{*}{ Lesion } & \multicolumn{3}{|c|}{ Preoperative } & \multicolumn{9}{|c|}{ Postoperative } \\
\hline & \multirow[b]{2}{*}{$M L$} & \multirow[b]{2}{*}{$I / E$} & \multirow[b]{2}{*}{$E L$} & \multicolumn{3}{|l|}{1} & \multicolumn{3}{|l|}{2} & \multicolumn{3}{|l|}{3} \\
\hline & & & & $M L$ & $I / E$ & $E L$ & $M L$ & $I / E$ & $E L$ & $\overline{M L}$ & $I / E$ & $E L$ \\
\hline $\begin{array}{l}\text { Sham control } \\
\text { (n) } \\
\text { Rostral CMA }\end{array}$ & $\begin{array}{l}73 \pm 42 \\
\text { (3) }\end{array}$ & $\begin{array}{l}8.6 \pm 1.3 \\
(3)\end{array}$ & $\begin{array}{l}194 \pm 77 \\
(3)\end{array}$ & $\begin{array}{l}40 \pm 31 \\
(3)\end{array}$ & $\begin{array}{l}8.3 \pm 0.3 \\
(3)\end{array}$ & $\begin{array}{l}164 \pm 71 \\
\text { (3) }\end{array}$ & $\begin{array}{l}47 \pm 9 \\
(3)\end{array}$ & $\begin{array}{l}7.3 \pm 0.6 \\
\text { (3) }\end{array}$ & $\begin{array}{l}167 \pm 53 \\
(3)\end{array}$ & $\begin{array}{l}40 \pm 11 \\
(3)\end{array}$ & $\begin{array}{l}8.0 \pm 0.5 \\
(3)\end{array}$ & $\begin{array}{l}177 \pm 36 \\
(3)\end{array}$ \\
\hline $\begin{array}{l}\text { (ventral) } \\
\text { (n) } \\
\text { Rostral CMA }\end{array}$ & $\begin{array}{l}47 \pm 8 \\
(9)\end{array}$ & $\begin{array}{l}12.3 \pm 2.0 \\
\text { (9) }\end{array}$ & $\begin{array}{l}220 \pm 33 \\
(9)\end{array}$ & $\overline{(0)}$ & $\overline{(0)}$ & $\overline{(0)}$ & $\begin{array}{l}119 \\
(1)\end{array}$ & $\begin{array}{l}8 \\
\text { (1) }\end{array}$ & $\begin{array}{l}215 \\
(1)\end{array}$ & $\overline{(0)}$ & $\overline{(0)}$ & $\overline{(0)}$ \\
\hline (n) & $\begin{array}{l}48 \pm 12 \\
(3)\end{array}$ & $11.6 \pm 1.8$ & $\begin{array}{l}202 \pm 34 \\
(3)\end{array}$ & $\overline{(0)}$ & $\overline{(0)}$ & $\overline{(0)}$ & $\begin{array}{l}51 \\
(1)\end{array}$ & $\begin{array}{l}12 \\
(1)\end{array}$ & $\begin{array}{l}196 \\
(1)\end{array}$ & $\begin{array}{l}37 \\
(1)\end{array}$ & $\begin{array}{l}13 \\
(1)\end{array}$ & $\begin{array}{l}203 \\
(1)\end{array}$ \\
\hline $\begin{array}{l}\text { BLA } \\
\text { (n) }\end{array}$ & $\begin{array}{l}59 \pm 15 \\
(6)\end{array}$ & $\begin{array}{c}12.8 \pm 2.8 \\
(6)\end{array}$ & $\begin{array}{l}227 \pm 31 \\
(6)\end{array}$ & $\begin{array}{l}50 \pm 7 \\
(6)\end{array}$ & $\begin{array}{l}11.0 \pm 1.4 \\
(6)\end{array}$ & $\begin{array}{l}236 \pm 38 \\
(6)\end{array}$ & $\begin{array}{l}65 \pm 21 \\
(6)\end{array}$ & $\begin{array}{l}8.2 \pm 1.2 \\
(6)\end{array}$ & $\begin{array}{l}247 \pm 51 \\
(6)\end{array}$ & $\begin{array}{l}38 \pm 9 \\
(6)\end{array}$ & $\begin{array}{l}12.6 \pm 1.5 \\
(6)\end{array}$ & $\begin{array}{l}222 \pm 39 \\
(6)\end{array}$ \\
\hline
\end{tabular}


TABLE II

Anogenital investigations by male hamsters during mating tests before and after amygdaloid lesions

Mean sec. sniffing/licking \pm S.E.M.

\begin{tabular}{lcccc}
\hline Lesion & Preoperative & \multicolumn{2}{c}{ Postoperative } & \\
\cline { 3 - 4 } & & $I$ & 2 & 3 \\
\hline Sham control $(\mathrm{n}=3)$ & $22.1 \pm 2.4$ & $15.5 \pm 3.5$. & $19.0 \pm 4.7$ & $15.0 \pm 5.0$ \\
Rostral CMA (ventral) $(\mathrm{n}=9)$ & $23.6 \pm 2.3$ & $4.3 \pm 1.8^{*}$ & $2.2 \pm 0.9^{*}$ & $4.6 \pm 1.4^{*}$ \\
Rostral CMA (dorsal) $(\mathrm{n}=3)$ & $24.3 \pm 1.5$ & $7.4 \pm 5.7^{*}$ & $7.3 \pm 3.2^{*}$ & $6.1 \pm 4.3^{*}$ \\
BLA $(\mathrm{n}=6)$ & $30.2 \pm 3.4$ & $26.1 \pm 4.6$ & $24.3 \pm 3.0$ & $28.1 \pm 4.0$
\end{tabular}

* $P<0.01$, Wilcoxon T-test between preoperative and postoperative measures.

third test of the postoperative series. After histological observations were completed, however, it was apparent that the right CMA lesion in this animal, although placed in the dorsal portion of $\mathrm{M}$, was quite small and spared a significant portion of rostral $\mathbf{M}$ on that side. In comparison, the left CMA lesion of hamster 826 , as well as those lesions in the 2 other hamsters of this experimental group, were much more extensive, damaging a major portion of $M$ throughout its extent while sparing its ventral surface (e.g. Fig. $1 \mathrm{C}_{\mathrm{iii}}$ ). Overall, male hamsters with rostral CMA lesions damaging a majority of either the dorsal or ventral portion of $\mathrm{M}$ bilaterally, showed the same compiete loss of copulatory behavior as animals with total bilateral destruction of $M$ had in our earlier study ${ }^{36}$. In contrast, male hamsters with bilateral BLA lesions, some of which damaged portions of $\mathrm{C} 1$ and $\mathrm{C} 2$, continued to display normal copulatory behavior during all postoperative tests, and showed no changes in the normal temporal patterning of mounts, intromissions, and ejaculations, during those tests. As expected, all sham operates also continued to mate normally during postoperative tests.

The loss of copulatory behavior in male hamsters with rostral CMA lesions, whether ventral or dorsal, was also accompanied by a significant decrease in the amount of time these males spent sniffing and licking the anogenital region of the receptive female during postoperative mating tests $(P<0.01$, Wilcoxon T-trest) (Table II). During the same tests, the amount of time these males spent sniffing and licking the female's flank or head region remained unchanged from preoperative levels. These males also displayed a tendency to bite and mouth the hindlimbs and tail of the female, similar to behavior seen in vomeronasal-deafferented or bulbectomized male hamsters which show an absence of copulatory behavior ${ }^{58}$. The slightly longer duration and increased variability in anogenital investigation displayed by males with dorsal lesions of the rostral CMA than by those with ventral lesions is chiefly accounted for by one animal, hamster 826 , the same male in the dorsal lesion experimental group that resumed copulatory behavior during postoperative tests, and whose brain lesion was unilaterally incomplete. With the exception of this hamster, males with rostral CMA lesions that damaged the dorsal portion of $M$ and spared the ventral surface of the brain were indistinguishable in their postoperative copulatory and investigatory deficits from males with rostral CMA lesions that damaged the ventral part of $M$ and extended to its ventral surface. Although there was an obvious difference between the baseline preoperative levels of anogenital investigation for the sham control group $(\bar{X}=22.1)$ and for those males with bilateral BLA lesions $(\bar{X}=30.2)$, it is clear that animals in both these experimental groups continued to display preoperative levels of anogenital investigation during all postoperative tests, in marked contrast to the decrease in anogenital investigation by males with rostral CMA lesions.

\section{DISCUSSION}

The results of our autoradiographic analyses are in close agreement with previous studies ${ }^{4,9,52}$ and confirm the normal trajectories of efferents in the hamster from the MOB and AOB to the amygdala and caudal piriform lobe. Vomeronasal projections 
from AOB travel along the ventral surface of the nucleus of the accessory tract, forming a crescentshaped terminal field, and move caudally along the ventromedial surface of the CMA, as they terminate in the superficial plexiform layers of the medial (M) and posteromedial (C3) nuclei of the amygdala*. Olfactory fibers from the MOB travel along the ventrolateral surface of the CMA, terminating in the superficial plexiform layers of the anterior cortical (C1) and posterolateral cortical (C2) nuclei of the amygdala, in addition to the caudal piriform cortex, the lateral entorhinal cortex, and the entorhinal transition area. Our autoradiographic observations in animals with rostral CMA lesions which damage the ventral part of $M$ and extend to the ventral surface of the brain, demonstrate that while olfactory inputs to areas caudal to this type of lesion remain intact, vomeronasal input to $\mathrm{C} 3$ in these animals is interrupted. However, in animals with rostral CMA lesions which destroy the dorsal part of $M$ but spare the ventral surface, vomeronasal input to $\mathrm{C} 3$ is not interrupted. Since male hamsters with dorsal $\mathbf{M}$ lesions display the same deficits in copulatory and investigatory behavior as males with ventral lesions, we conclude that the mating deficits seen after rostral CMA lesions are due primarily to destruction of $\mathrm{M}$, and not to the interruption of vomeronasal or olfactory inputs to areas caudal to the site of the lesion.

Normal mating behavior in male hamsters is dependent on odor cues provided by a receptive female ${ }^{44}$. Attraction to, and prolonged investigation of these odor cues, which include the female's vaginal secretion, facilitate the male's copulatory response ${ }^{8,42}$, and are mediated by both vomeronasal organ input to the $A O B$ and olfactory receptor input to the $\mathrm{MOB}^{47}$. While deafferentation of either vomeronasal or olfactory receptors alone is insufficient in a majority of animals to disrupt male mating behavior, combined deafferentation of both vomeronasal and olfactory systems ${ }^{48,58}$, or destruction

\footnotetext{
* In addition to AOB projections to the nucleus of the accessory olfactory tract, $M$ and $C 3$, previous studies ${ }^{9,52}$ and examinations of other material prepared in our laboratory also identified a small fascicle of labelled AOB efferents in the stria terminalis that eventually gave rise to a small terminal field in the dorsocaudal part of the bed nucleus of the stria terminalis.
}

of both the AOB and $\mathrm{MOB}^{44}$, severely diminishes the male hamster's sniffing and licking investigation of the female's anogenital region during mating tests, and completely eliminates the male's copulatory response. Additionally, bilateral transections of $A O B$ and MOB efferents in the accessory and lateral olfactory tracts at levels rostral to the CMA, which spare olfactory input to the rostral piriform cortex and olfactory tubercle, have been shown to abolish male hamster copulatory behavior ${ }^{10}$. Therefore, although the medial amygdaloid nucleus is primarily a 'vomeronasal' recipient area, the above evidence suggests that medial nucleus lesions must in some way interrupt both vomeronasal and olfactory inputs critical for this behavior.

There are several indirect routes by which olfactory information may influence activity in the medial amygdaloid nucleus. In the rat these inputs reach $M$ from several secondary targets of the olfactory system, including intra-amygdaloid connections from $\mathrm{C} 1$ and $\mathrm{C} 2$ to $\mathrm{M}^{31}$, and piriform cortex efferents to the endopiriform nucleus, which in turn projects to $\mathrm{M}^{30}$. The intra-amygdaloid projections of $\mathrm{Cl}$ and $\mathrm{C} 2$ to $\mathrm{M}$ have recently been confirmed in the hamster ${ }^{29}$. Additionally, the demonstration in this experiment and in silver degeneration studies in this laboratory, of a thin olfactory terminal field ventromedial to the most anterior portion of $\mathbf{M}$, suggests that perhaps second-order olfactory fibers reach $\mathbf{M}$ directly as well. However, the sparse and limited nature of this olfactory projection, especially when compared with the extensive vomeronasal input to the remainder of $M$, make it seem more likely that olfactory information reaches $\mathrm{M}$ primarily through afferents from $\mathrm{C} 1, \mathrm{C} 2$ or the endopiriform nucleus.

The behavioral importance of vomeronasal and olfactory inputs to the medial nucleus in the hamster is reflected in the efferent projections of this nucleus compared to those of other vomeronasal- or olfactory-recipient nuclei in the amygdala ${ }^{28,29}$. Efferents of $\mathrm{M}$ in the hamster project directly via the stria terminalis to preoptic and medial hypothalamic areas, including the preoptic continuation of the bed nucleus of the stria terminalis, the medial preopticanterior hypothalamic junction (MPOAH), and the ventromedial hypothalamic nucleus. These are brain areas that, like $M$, have been shown to contain 
neurons which concentrate steroid hormones ${ }^{51,57}$, and have been implicated in the control of reproductive physiology and behavior ${ }^{33,39,46}$. In particular, androgen-binding neurons in MPOAH have been shown from a wide variety of stimulation ${ }^{38}$, hormone implant ${ }^{24}$, and brain lesion ${ }^{17,21}$ experiments to play a major role in mediating copulatory behavior in almost all male vertebrates ${ }^{25}$. In contrast to $\mathrm{M}$, neurons of $\mathrm{Cl}$ and $\mathrm{C} 2$, and $\mathrm{C} 3$, send efferents primarily to other secondary targets of the olfactory or vomeronasal systems, respectively, and do not project directly to MPOAH ${ }^{28,29}$.

However, an alternate route exists by which vomeronasal and olfactory information may exert a relatively direct influence upon activity in MPOAH. Recent electrophysiological evidence in the hamster suggests that cells in $\mathrm{C} 3$ project to and activate neurons in the deeper layers of the amygdala, probably in the amygdalo-hippocampal area (AHA) of the amygdala ${ }^{41}$. Neuroanatomical studies of intraamygdaloid connections in the rat ${ }^{31}$ and hamster ${ }^{29}$ have also revealed that neurons in $\mathrm{Cl}$ project to AHA. Since cells in AHA, like those in M, project to MPOAH via the stria terminalis ${ }^{30}$, efferents from $\mathrm{C} 3$ and $\mathrm{C} 1$ to AHA constitute another pathway by which vomeronasal and olfactory information may reach MPOAH. Furthermore, AHA, like M, is a major androgen-binding brain area ${ }^{51,54}$, and the electrophysiological characteristics of neurons in this nucleus have been shown in the rat to be influenced by the presence of testosterone ${ }^{26}$. These observations suggest a possible explanation for similarities observed between mating deficits seen after dorsal $\mathbf{M}$ lesions and those observed following $\mathbf{M}$ lesions which extend to the ventral surface of the brain. Dorsal lesions of the medial nucleus at their caudal extent damaged the amygdaloid exit of the stria terminalis, and probably interrupted strial efferents from both $\mathrm{M}$ and AHA directed toward MPOAH. Ventral lesions of the medial nucleus, which often damaged part of $\mathrm{Cl}$, interrupted vomeronasal input to both $\mathrm{M}$ and $\mathrm{C} 3 / \mathrm{AHA}$, and probably interrupted olfactory input to $\mathrm{AHA}$ via $\mathrm{Cl}$ as well. It is possible therefore that ventral and dorsal lesions of the medial nucleus were equally effective in disrupting mating behavior because they, respectively, interrupted the chemosensory inputs or strial efferents of both $\mathrm{M}$ and $\mathrm{AHA}$, and not just $\mathrm{M}$ alone.
This hypothesis, however, can be disputed on the basis of several observations. First, it is clear from previous experiments ${ }^{34,36}$ that bilateral caudal CMA lesions, which damage the caudal end of $\mathrm{M}$, the exit of the stria terminalis, and a major portion of $\mathrm{C} 3$ and $\mathrm{AHA}$, lead to alterations in mating behavior that are fundamentally different from the complete elimination of the behavior seen following bilateral rostral CMA lesions. In contrast to males with rostral CMA lesions, male hamsters with caudal CMA lesions continue to display copulatory behavior during postoperative tests, although they do show changes in their temporal patterning of the copulatory sequence, specifically an increased latency to mount and an increase in the time between intromissions. Similarly, male hamsters with bilateral knife cuts or lesions interrupting the stria terminalis ${ }^{34}$ continue to mate in postoperative tests but show similar alterations in temporal patterning. Since both caudal CMA lesions and stria terminalis lesions interrupt efferents to MPOAH from both $\mathrm{M}$ and AHA, but neither completely abolish mating behavior, it is difficult to ascribe those mating deficits seen after dorsal lesions of $M$ to an interruption of strial efferents from M and AHA. Rather, these observations suggest that in the hamster some neurons in M or AHA may project to MPOAH or other medial hypothalamic areas by way of a nonstrial pathway, and that these non-strial amygdaloid efferents may play a significant role in mediating chemosensory control of male copulatory behavior. Other studies in our laboratory ${ }^{35}$ have confirmed the existence and functional importance of a ventral non-strial projection from $\mathrm{M}$, but not from AHA, to the preoptic continuation of the bed nucleus of the stria terminalis. On the basis of these findings, we conclude that copulatory and investigatory deficits seen after dorsal or ventral lesions of $M$ are due primarily to destruction of the medial nucleus itself, with its complement of strial and non-strial efferents to the bed nucleus of the stria terminalis and the medial preoptic-anterior hypothalamic junction, although the interruption of strial efferents from AHA may in some way contribute to these deficits.

In contrast to thalamocortical olfactory pathways, which in rodents appear to be involved in learned discriminative responses to odor cues ${ }^{13,50}$, we suggest that vomeronasal and olfactory pathways 
to the amygdala mediate behavior by attaching a learned motivational significance to specific odors, in the case of male hamster mating behavior those sexually-relevant odors associated with a female hamster. Furthermore, observations that neurons of the CMA, particularly those in M and AHA, are major targets for the actions of androgens $\mathrm{s}^{51,54}$ and estrogens ${ }^{32,57}$ in the mammalian brain, complement evidence that the motivational qualities of certain odors may be influenced by the presence of steroid hormones. For example, even though castrated male rats can be trained to discriminate between the odors of estrous and non-estrous females ${ }^{6}$, these males unlike gonadally-intact animals, no longer display a preference for the odors of an estrous female ${ }^{5,56}$. Similarly, the male hamsters's responsiveness to the female's vaginal secretion is dependent on the presence of testosterone; castrated male hamsters show no interest in these odors ${ }^{18}$. These studies, considered together with our own, suggest that vomeronasal and olfactory pathways to nuclei of the CMA, which contain androgen-binding neurons, are the neural substrate by which steroid hormones influence the motivational qualities of odor cues.

In view of the possible influence of steroid hormones on the physiology of neurons in the 'vomeronasal' amygdala, it is interesting to note that this

\section{REFERENCES}

1 Bellringer, J. F., Pratt, H. P. M. and Keverne, E. B., Involvement of the vomeronasal organ and prolactin in pheromonal induction of delayed implantation in mice, J. Reprod. Fert., 59 (1980) 223-228.

2 Beltramino, C. and Taleisnik, S., Facilitatory and inhibitory effects of electrochemical stimulation of the amygdala on the release of luteinizing hormone, Brain Research, 144 (1978) 95-107.

3 Beltramino, C. and Taleisnik, S., Dual action of electrochemical stimulation of the bed nucleus of the stria terminalis on the release of LH, Neuroendocrinology, 30 (1980) 238-242.

4 Broadwell, R. D., Olfactory relationships of the telencephalon and diencephalon in the rabbit. I. An autoradiographic study of the efferent connections of the main and accessory olfactory bulbs. J. comp. Neurol., 163 (1975) 329-346.

5 Brown, R. E., Hormonal control of odor preferences and urine marking in male and female rats, Physiol. Behav., 20 (1978) 21-24.

6 Carr, W. J. and Caul, W. F., The effect of castration in rat upon the discrimination of sex odours, Anim. Behav., 10 (1962) 20-27. relationship may be reciprocal. In recent studies, vomeronasal sensory cues have been increasingly implicated in the control of pheromonally-induced changes in female mammalian reproductive physio$\operatorname{logy}^{22}$. These include the male urine-induced reflex ovulation of anovulatory female rats ${ }^{23}$, the suppressive effects of all-female grouping on estrous cycling in mice (Lee-Boot effect) ${ }^{49}$, and the blocking of pregnancy in female mice by contact with strange male urine (Bruce effect) ${ }^{1}$. Because of the important role of $\mathrm{M}$ and its preoptic and medial hypothalamic targets in the control of anterior pituitary function ${ }^{2}$, $3,14,45$, chemosensory inputs to the CMA probably mediate neuroendocrine events underlying these changes in reproductive physiology, as well as immediate chemosensory control of maternal behavior $15,16,40$, sexual behavior ${ }^{17,19}$, territorial aggres$\operatorname{sion}^{34,43}$ and perhaps also feeding behavior ${ }^{37}$. In the male hamster, vomeronasal and olfactory inputs to the amygdala may therefore mediate pheromonallyinduced neuroendocrine events associated with male reproductive development as well as immediate chemosensory control of mating behavior.

\section{ACKNOWLEDGEMENTS}

This research was supported in part by NRSA Grant T32-MH14279 to M.N.L. and by NIH Grant R01-NS14071 to S.S.W.

7 Cowan, W. M., Gottlieb, D. I., Hendrickson, A. E., Price, J. L. and Woolsey, T. A., The autoradiographic demonstration of axonal connections in the central nervous system, Brain Research, 37 (1972) 21-51.

8 Darby, E. M., Devor, M. and Chorover, S., A presumptive sex pheromone in the hamster: some behavioral effects, J. Comp. Physiol. Psych., 88 (1975) 496-502.

9 Davis, B. J., Macides, F., Youngs, W. M., Schneider, S. P. and Rosene, D. L., Efferents and centrifugal afferents of the main and accessory olfactory bulbs in the hamster, Brain Res. Bull., 3 (1978) 59-72.

10 Devor, M., Components of mating dissociated by lateral olfactory tract transection in male hamsters, Brain Research, 64 (1973) 437-441.

11 Devor, M., Fiber trajectories of olfactory bulb efferents in the hamster, J. comp. Neurol., 166 (1976) 31-48.

12 Devor, M., Neuroplasticity in the rearrangement of olfactory tract fibers after neonatal transection in hamsters, J. comp. Neurol., 166 (1976) 49-72.

13 Eichenbaum, H., Shedlack, K. J. and Eckmann, K. W., Thalamocortical mechanisms in odor-guided behavior. I. Effects of lesions of the mediodorsal thalamic nucleus and frontal cortex on olfactory discrimination in the rat, Brain Behav. Evol., 17 (1980) 255-275. 
14 Ellendorf, F. and Parvizi, N., Role of extrahypothalamic centers in neuroendocrine integration. In M. Motta (Ed.), The Endocrine Functions of the Brain, Raven Press, New York, 1980, pp. 297-325.

15 Fleming, A. S., Vaccarino, F. and Luebke, C., Amygdaloid inhibition of maternal behavior in the nulliparous female rat, Physiol. Behav., 25 (1980) 731-743.

16 Fleming, A., Vaccarino, F., Tambosso, L. and Chee, P., Vomeronasal and olfactory system modulation of maternal behavior in the rat, Science, 203 (1979) 372-374.

17 Giantonio, G. W., Lund, N. L. and Gerall, A. A., Effect of diencephalic and rhinencephalic lesions on the male rat's sexual behavior, J. comp. Physiol. Psych., 73 (1970) $38-46$.

18 Gregory, E., Engle, K. and Pfaff, D., Male hamster preference for odors of female hamster vaginal discharges: studies of experiential and hormonal determinants, $J$. comp. Physiol. Psych., 89 (1975) 442-446.

19 Harris, V. and Sachs, B. D., Copulatory behavior in male rats following amygdaloid lesions, Brain Research, 86 (1975) 514-518.

20 Haug, F.-M. S., Sulphide silver pattern and cytoarchitectonics of parahippocampal areas in the rat, Advanc. Anat. Embryol. Cell Biol., 52 (1976) 1-73.

21 Heimer, L. and Larsson, K., Impairment of mating behavior in male rats following lesions in the preopticanterior hypothalamic continuum, Brain Research, 3 (1967) 248-263.

22 Johns, M. A., The role of the vomeronasal system in mammalian reproductive physiology. In D. MullerSchwarze and R. M. Silverstein (Eds.), Chemical Signals, Vertebrates and Aquatic Invertebrates, Plenum Press, New York, 1980, pp. 341-364.

23 Johns, M. A., Feder, H. H., Komisaruk, B. R. and Mayer A. D., Urine-induced reflex ovulation in anovulatory rats may be a vomeronasal effect, Nature (Lond.), 272 (1978) 446-448.

24 Johnston, P. and Davidson, J. M., Intracerebral androgens and sexual behavior in the male rat, Horm. Behav., 3 (1973) 345-357.

25 Kelley, D. B. and Pfaff, D. W., Generalization from comparative studies on neuroanatomical and endocrine mechanisms of sexual behavior. In J. B. Hutchinson (Ed.), Biological Determinants of Sexual Behavior, Wiley, New York, 1978, pp. 225-254.

26 Kendrick, K. M. and Drewett, R. F., Testosterone reduces refractory period of stria terminalis neurons in the rat brain, Science, 204 (1979) 877-879.

27 Kendrick, K. M. and Drewett, R. F., Testosteronesensitive neurons respond to oestradiol but not to dihydrotestosterone, Nature (Lond.), 286 (1980) 67-68.

28 Kevetter, G. A. and Winans, S. S., Connections of the corticomedial amygdala in the golden hamster. I. Efferents of the 'vomeronasal amygdala', J. comp. Neurol., 197 (1981) 81-98.

29 Kevetter, G. A. and Winans, S. S., Connections of the corticomedial amygdala in the golden hamster. II. Efferents of the 'olfactory amygdala', J. comp. Neurol., 197 (1981) 99-111.

30 Krettek, J. E. and Price, J. L., Amygdaloid projections to subcortical structures within the basal forebrain and brainstem in the rat and cat, J. comp. Neurol., 178 (1978) 225-254.

31 Krettek, J. E. and Price, J. L., A description of the amyg- daloid complex in the rat and cat with observations on intra-amygdaloid axonal connections, $J$. comp. Neurol., 178 (1978) 255-280.

32 Krieger, M. S., Morrell, J. I. and Pfaff, D. W., Autoradiographic localization of estradiol-concentrating cells in the female hamster brain, Neuroendocrinology, 22 (1976) 193-205.

33 Larsson, K., Features of the neuroendocrine regulation of masculine sexual behavior. In C. Beyer (Ed.), Endocrine Control of Sexual Behavior, Raven Press, New York, 1979, pp. 77-163.

34 Lehman, M. N., Kevetter, G. A. and Powers, J. B., Sexual and aggressive behavior in male hamsters after lesions of the corticomedial amygdala, Neurosci. Abstr., 4 (1978) 251

35 Lehman, M. N. and Winans, S. S., Amygdaloid efferents to the bed nucleus of the stria terminalis and the medial preoptic area controlling male hamster sexual behavior: combined HRP and behavioral analyses, Neurosci. Abstr., 6 (1980) 460.

36 Lehman, M. N., Winans, S. S. and Powers, J. B., Medial nucleus of the amygdala mediates chemosensory control of male hamster sexual behavior, Science, 210 (1980) 557-560.

37 Lewinska, M. K., Selective deficit in feeding behavior following antero-medial amygdaloid lesions in cats, Acta physiol. pol., 16 (1975) 532-541.

38 Malsbury, C. W., Facilitation of male rat copulatory behavior by electrical stimulation of the medial preoptic area, Physiol. Behav., 7 (1971) 797-805.

39 Malsbury, C. W. and Pfaff, D. S., Neural and hormonal determinants of mating behavior in adult male rats. A review. In L. V. DiCara (Ed.), Limbic and Autonomic Nervous System Research, Plenum Press, New York, 1974, pp. $85-136$.

40 Marques, D. M., Roles of the main olfactory and vomeronasal systems in the response of the female hamster to young, Behav. Neurol. Biol., 26 (1979) 311-329.

41 Meredith, M., The vomeronasal organ and accessory olfactory system in the hamster. In D. Muller-Schwarze and R. M. Silverstein (Eds.), Chemical Signals, Vertebrates and Aquatic Invertebrates, Plenum Press, New York, 1980, pp. 303-326.

42 Murphy, M., Effects of female hamster vaginal discharge on the behavior of male hamsters, Behav. Biol., 9 (1973) 367-375.

43 Murphy, M. R., Olfactory stimulation and olfactory bulb removal: effects on territorial aggression in male Syrian golden hamsters, Brain Research, 113 (1976).

44 Murphy, M. and Schneider, G. E., Olfactory bulb removal eliminates mating behavior in the male golden hamster, Science, 167 (1969) 302-303.

45 Peters, J. A. and Gala, R. R., The effect of corticomedial amygdaloid lesions on prolactin secretion in male and female rats, Endocrinology, 106 (1980) 1665-1669.

46 Pfaff, D. W., Estrogens and Brain Function, Springer, New York, 1980, pp. 106-127.

47 Powers, J. B., Fields, R. B. and Winans, S. S., Olfactory and vomeronasal system participation in male hamster's attraction to female vaginal secretions, Physiol. Behav., 22 (1979) 77-84.

48 Powers, J. B. and Winans, S. S., Vomeronasal organ: critical role in mediating sexual behavior of the male hamster, Science, 187 (1975) 961-963. 
49 Reynolds, J. and Keverne, E. B., The accessory olfactory system and its role in the pheromonally mediated suppression of oestrus in grouped mice, J. Reprod. Fert., 57 (1979) 31-35.

50 Sapolsky, R. M. and Eichenbaum, H., Thalamocortical mechanisms in odor-guided behavior. II. Effects of lesions of the mediodorsal thalamic nucleus and frontal cortex on odor preferences and sexual behavior in the hamster, Brain Behav. Evol., 17 (1980) 276-290.

51 Sar, M. and Stumpf, W. E., Distribution of androgenconcentrating neurons in rat brain. In W. E. Stumpf and L. D. Grant (Eds.), Anatomical Neuroendocrinology, Karger, Basel, 1975, pp. 120-133.

52 Scalia, F. and Winans, S. S., The differential projections of the olfactory bulb and accessory olfactory bulb in mammals, J. comp. Neurol., 161 (1975) 31-56.

53 Scott, J. W., McBride, R. L. and Schneider, S. P., The organization of projections from the olfactory bulb to the piriform cortex and olfactory tubercle in the rat, $J$. comp. Neurol., 194 (1980) 519-534.
54 Sheridan, P. J., The nucleus interstitialis striae terminalis and the nucleus amygdaloideus medialis: Prime targets for androgen in the rat forebrain, Endocrinology, 101 (1979) 130-136.

55 Skeen, L. C. and Hall, W. C., Efferent projections of the main and accessory olfactory bulb in the tree shrew (Tupaia glis), J. comp. Neurol., 172 (1977) 1-35.

56 Stern, J. J., Responses of male rats to sex odors, Physiol. Behav., 5 (1970) 519-524.

57 Stumpf, W. E., Sar, M. and Keefer, D. A., Atlas of estradiol target cells in rat brain. In W. E. Stumpf and L. D. Grant (Eds.), Anatomical Neuroendocrinology, Karger, Basel, 1975, pp. 104-119.

58 Winans, S. S. and Powers, J. B., Olfactory and vomeronasal deafferentation of male hamsters: histological and behavioral analyses, Brain Research, 126 (1977) 325-344.

59 Wysocki, C. J., Neurobehavioral evidence for the involvement of the vomeronasal system in mammalian reproduction, Neurosci. Biobehav. Rev., 3 (1979) 301-341. 